\title{
MATA ATLÂNTICA: UMA ABORDAGEM GEOGRÁFICA
}

PEREIRA, Anísio Baptista ${ }^{1}$

Recebido em: 2008-10-29

Aprovado em: 2009-01-19

ISSUE DOI: $10.3738 / 1982.2278 .152$

RESUMO: Para os ecólogos a mata Atlântica é um grande ecossistema ou um bioma. Sob a ótica geográfica, ela é um tipo de vegetação subcontinental que faz parte de um sistema fisiográfico tropical úmido e que ocupa um considerável espaço geográfico no Brasil e em alguns países vizinhos. Geógrafos, biólogos e outros cientistas vêm estudando sua evolução no tempo geológico, sob o foco dos paleoclimas do Quaternário. Todavia, ela está se transformando, no tempo histórico recente, devido a uma considerável devastação e impactos ambientais, ao mesmo tempo em que vem atraindo a atenção de pesquisadores e ecoturistas. Por todos esses motivos, os órgãos governamentais passaram a adotar políticas conservacionistas que visam preservar o que dela resta. Este artigo procura abordar esses aspectos atinentes à mata Atlântica.

Palavras-chave: Mata Atlântica. Meio Ambiente. Parques nacionais. Biogeografia.

\section{ATLANTIC RAIN FOREST: A GEOGRAPHIC APPROACH}

SUMMARY : According to the ecologist, the tropical rain Forest is a big ecosystem or a biome. Under the geographic optics, it is a type of sub continental vegetation that it is part of the humid tropical physiographic system, and occupies a considerable geographic space in Brazil and in some neighboring countries. Geographers, biologists and other scientists have been studying this evolution in geological time, under the focus of the paleoclimates of the Quaternary. However, it is transforming, in recent historical time, due to a considerable devastation and environmental impacts, in the same time, it has been attracting the researchers and ecotourists' attention. For all this reasons, the government organs adopt the conservationist policies that aim to preserve what there is left. This article tries to approach these aspects concerning the Atlantic rain forest.

Keywords: Atlantic rain forest. Environment. National parks. Biogeography.

\section{INTRODUÇÃO}

MATA ATLÂNTICA é o nome popular dado a floresta tropical atlântica que ocupa a fachada oriental do Brasil e grande parte da bacia do Paraná. Rumo ao interior, de norte a sul, ela limita-se com tipos de vegetação bem diferentes: no Nordeste ela se limita com a caatinga; na Região Sudeste, com o cerrado, e na Região Sul, com a Floresta de Araucárias e os campos limpos. Como toda floresta tropical, ela impressiona pela sua densidade e pela sua heterogeneidade ou variedade em espécies (biodiversidade). Ao longo dos séculos, desde 1500, ela tem fornecido grande número de preciosas madeiras para construções, para mobiliário e para outros fins. Sua rica

\footnotetext{
1 Ex-professor de Geografia Física na Universidade de Sorocaba. Ex-professor de Biogeografia na PUC-SP.
} 
flora nos fornece, também, inúmeras espécies de plantas ornamentais e medicinais.

Essa formação vegetal já ocupou um espaço geográfico bem maior, porém, está hoje muito reduzida em área (7,2\% conforme o INPE). O acesso e a penetração no seu interior é mais fácil nas áreas de preservação ambiental, como parques nacionais e estaduais e reservas ecológicas. Da mesma forma, a prática do ecoturismo e dos esportes de aventura, com monitoramento de guias credenciados, vem aumentando muito entre nós, permitindo aos interessados um contato direto com esse tipo de vegetação, e com outras atrações que ela abriga, como rios encachoeirados, penhascos, cavernas, etc.

Grande parte dessa floresta remanescente já teria sido devastada, apresentandose atualmente na condição de mata secundária. As matas originais acham-se acantonadas nas gargantas do relevo, nos grotões e nas escarpas altas e muito íngremes, lugares de difícil acesso, onde a ocupação humana torna-se quase inviável e desinteressante.

\section{CLIMAS}

A Mata Atlântica deve sua existência a tipos climáticos que variam de climas quentes e úmidos a moderadamente frios (mesotérmicos), reinantes na fachada atlântica brasileira. Temperaturas altas, elevada umidade relativa do ar, precipitações abundantes, nevoeiros freqüentes em algumas áreas, e intensa luminosidade, caracterizam tais climas. A diversidade do relevo contribui, regionalmente, para as modificações estruturais da mata.

Desde o litoral potiguar até o nordeste do Rio Grande do Sul, sucedem-se vários tipos climáticos, em consonância com as variações de latitude e, secundariamente, de relevo. As temperaturas médias decrescem de norte a sul, enquanto os índices pluviométricos diminuem do litoral para o interior, ressalvando-se as influências geográficas. No sentido norte-sul, a sequiência de tipos climáticos é a seguinte (BERNARDES, 1960):

Clima As' (clima tropical com chuvas de outono-inverno. Sua tropicalidade inverte o período chuvoso, pois, no inverno verifica-se a penetração da massa de ar Polar atlântica $(\mathrm{Pa})$, procedente do Atlântico Sul, próximo à Argentina, e, seguindo a rota oceânica, junta-se aos ventos alíseos de Sudeste, produzindo chuvas abundantes. Rumo ao interior, as precipitações diminuem progressivamente. $\mathrm{O}$ período chuvoso vai de fevereiro a julho, enquanto o período seco estende-se de agosto a janeiro O clima As' abrange a fixa litorânea do Nordeste, desde o sul do Rio Grande 
do Norte até o Recôncavo Baiano.

Clima Af (clima quente e superúmido sem estação seca). Por ser bastante chuvoso, tem características equatoriais. Estende-se desde o Recôncavo Baiano até o extremo norte do Espírito Santo. Na Região Sudeste ele ocorre na baixa e média encosta da serra do Mar.

Clima Am (clima quente e superúmido com curta estação seca). É também muito chuvoso e, normalmente, sucede o clima Af no sentido do interior, tanto no trecho sul-baiano como na Região Sudeste; na maioria dos casos, a interiorização do clima implica numa diminuição da pluviosidade.

Clima $\mathrm{Cw}$ (clima tropical de altitude). É um clima tropical com características mesotérmicas, pois apresenta verões brandos e chuvosos e invernos secos e frios, com ocorrência eventual de geadas, nas latitudes mais propícias. Esse tipo climático ocorre nas áreas serranas da Região Sudeste. Também os enclaves de Mata de Araucárias existentes nesta região estão relacionados a esse clima.

Climas Cfa e Cfb (climas mesotérmicos com chuvas regularmente distribuídas ao longo do ano). São climas subtropicais que apresentam temperaturas baixas no inverno, devido à influência das latitudes extratropicais. No período hibernal as geadas são freqüentes, e as nevadas esporádicas e de ocorrência localizada. Por causa do frio mais intenso, nos pontos mais elevados da Serra Geral, a Mata Atlântica cede lugar à Floresta de Araucárias. Os climas subtropicais ocorrem em quase toda a Região Sul e no sul do Estado de São Paulo.

Todos os tipos climáticos acima referidos apresentam índices pluviométricos acima de $1000 \mathrm{~mm}$ /ano, pluviosidade suficiente para manter qualquer tipo de floresta. Entretanto, é preciso considerar o regime pluviométrico reinante nesta ou naquela região, neste ou naquele trecho florestal, pois a distribuição anual das chuvas é condição essencial para a formação e a manutenção das florestas.

Os climas quentes e superúmidos, além da abundante pluviosidade, apresentam elevada umidade relativa do ar e nevoeiros freqüentes, sobretudo nas áreas serranas, caracteres atmosféricos que conferem ao clima essa umidade benfazeja à vegetação florestal. A rigor, as geadas e as raras nevadas não fazem parte do quadro climático que caracteriza a floresta pluvial tropical de encosta, que é a verdadeira Mata Atlântica. 


\section{A MATA ATLÂNTICA E SUAS VARIAÇÕES FITOGEOGRÁFICAS}

Originalmente, essa formação vegetal estendia-se ao longo da faixa atlântica do Brasil, desde o Rio Trairi, no sul do Rio Grande do Norte, até as serras de Tapes e Herval, no Rio Grande do Sul, a oeste da Lagoa dos Patos. Estreita na Região Nordeste, ela alargava-se para o sul, até atingir sua largura máxima na bacia do Rio Paraná, penetrando, inclusive, em territórios paraguaio e argentino. Sucessivos episódios de devastação reduziram sua área primitiva, que atualmente fica em torno de 6 a $8 \%$ de sua área original.

Azevedo (1960) distinguiu, claramente, a existência de dois facies na floresta atlântica brasileira, vulgarmente conhecida por Mata Atlântica: a floresta tropical de caráter higrófilo e a floresta tropical do interior. A primeira formação é ombrófila e perenifólia, e a segunda é mesófila e subcaducifólia. Fisionomicamente, elas são idênticas durante o período chuvoso, mas um pouco diferentes durante o período seco, quando então fica patenteado o processo de caducifolia, que afeta principalmente a floresta do interior, onde a pluviosidade é menor. Azevedo (1960, p. 512), assim se expressou:

peculiaridades ligadas ao relevo, solos e clima permitem separar, entretanto, a floresta tropical de caráter higrófilo, representada pela floresta sempre verde que recobre a fachada atlântica do planalto brasileiro, da floresta tropical do interior, de características diversas que a distinguem nitidamente daquela mais diretamente influenciada pelo clima marítimo. Essa diferença reside, principalmente, na exuberância e grande umidade da floresta de caráter higrófilo e não se observa naquela que ocupa as áreas mais interiores.

Em geral, o limite entre elas situa-se nas cumeadas das serras, nas regiões Sul e Sudeste, que funcionam como uma espécie de “divisor" climático. Já na Região Nordeste, os topos aplainados do Planalto da Borborema não desempenham esse mesmo papel.Romariz (1964) concorda com Azevedo quando subdivide as florestas latifoliadas em floresta latifoliada tropical e floresta tropical úmida de encosta. De acordo com a referida autora, a verdadeira Mata Atlântica vem a ser o segundo tipo acima citado, que recobre, descontinuamente, as escarpas sublitorâneas do Planalto Brasileiro. Já a floresta latifoliada tropical (do interior) tem distribuição geográfica contínua desde o Rio Grande do Norte até o Paraná, e algumas ocorrências disjuntas em Santa Catarina e no Rio Grande do Sul. A Mata Atlântica higrófila, litorânea, na visão de Romariz (1964), ocorre em quatro áreas disjuntas, ao longo do litoral: a) Zona da Mata nordestina (PB, PE, AL); b) faixa litorânea sul-baiana, de Salvador a Ilhéus; c) zona Litorânea central do Espírito Santo; d) escarpas e serras sublitorâneas dos estados 
situados entre o Rio de Janeiro e Santa Catarina, já nos limites com o Rio Grande do Sul.

Essa dúplice divisão não é tão recente, pois Denis (1927), em Géographie Universelle, tome XV: Amérique Du Sud, num mapa das formações vegetais do continente, inserido entre as páginas 40 e 41, já distinguia diferenças na Mata Atlântica, admitindo a existência de uma forêt tropicale de versants e uma forêt tropicale de plaine, lado a lado. (Consideramos incorreto o emprego do termo plaine, quando o certo seria plateau).

Na Região Nordeste, ao norte do Rio São Francisco, há muito tempo, botânicos e geógrafos reconheceram a existência de dois padrões diferentes de floresta tropical. Referindo-se à Mata Atlântica, Vasconcelos Sobrinho (1970, p. 61) afirmou que,

estudando-a em sua presença no Nordeste, constatamos, já em 1941, duas diferenciações acentuadas, que denominamos Mata Úmida e Mata Sêca, diversificadas por algumas poucas espécies que lhes são peculiares mas, principalmente, por ser a Mata Úmida caracteristicamente perenifólia, enquanto que a Mata Sêca é semi-caducifólia, perdendo as árvores quase todas as folhas na estiagem, além de serem mais altas e de menor diâmetro que na Mata Úmida.

As espécies comuns às duas formações são numerosíssimas, porém, variando a freqüência de uma para outra. A Mata Seca estende-se desde o Rio Capibaribe, em Pernambuco, para o norte. Nos Estados do Rio Grande do Norte e da Paraíba a mata era descontínua, pois ocupava apenas os terrenos aluviais quaternários das várzeas, enquanto os terrenos mais arenosos e ressecados dos interflúvios eram ocupados por uma variedade de cerrado, regionalmente chamada de vegetação de "tabuleiro" (não confundir com a "Floresta de Tabuleiros", nome atribuído à Hiléia Baiana por Rizzini, 1979). Já a partir do Estado de Pernambuco ela passava a ser contínua, com raras interrupções.

Na faixa litorânea do sul da Bahia, desde o Rio de Contas até o Rio Mucuri, penetrando mesmo no norte do Estado do Espírito Santo, tem-se notado que a Mata Atlântica possui algumas afinidades fisiográficas e florísticas, e até faunísticas, com a Floresta Amazônica. Aí o relevo é tabuliforme, sedimentar e baixo (até $300 \mathrm{~m}$ ), representado, geologicamente, pelo Grupo Barreiras (Plioceno), que ocorre, também, em larga escala, na parte central do vale amazônico; o clima (tipo Af ou equatorial) é quente e superúmido, sem estação seca, como na zona litorânea da Amazônia; e para complementar, ambas as formações florestais possuem um elevado número de gêneros e espécies botânicos em comum. Joly; Leitão Filho; Silva (1991, p. 104) 
afirmam que

a identidade edafoclimática e geológica com áreas da planície amazônica é complementada por uma elevada similaridade estrutural e florística entre as florestas de terra firme da hiléia e as formações do sul da Bahia e norte do Espírito Santo.

Certamente por este motivo, alguns autores passaram a denominar esse segmento da Mata Atlântica de Hiléia Baiana.

No trecho florestal sul-baiano, ao sul do Rio Paraguaçu, a Mata Atlântica também apresentava nítidas variações fitogeográficas, no sentido litoral-interior; assim, próximo à costa ocorre a floresta higrófila perenifólia (Mata Atlântica stricto sensu), e mais para o interior, nas escarpas do planalto sul-baiano, ocorre uma floresta mesófila subcaducifólia, regionalmente conhecida por Mata-de-Cipó. A respeito dela, Domingues; Keller (1956, p. 106) afirmaram:

a vegetação da mata verdadeira cede lugar a um tipo de vegetação de transição: a mata-de-cipó. Não muito desenvolvida, essa mata atinge normalmente 15 a 20 metros de altura. É constituída essencialmente de árvores não muito grossas, em média com 25 centímetros de diâmetro, esguias e de copa relativamente pouco ramificada.

Na Bahia, a Mata-de-Cipó corresponde à Mata Seca, do Nordeste (RN, PB, PE), referida por Vasconcelos Sobrinho (1970). O porte das árvores é florestal. A vegetação é pobre em epífitas, mas muito rica em lianas (cipós lenhosos), e daí advindo o nome atribuído a essa mata. Transposta a escarpa do planalto, o clima torna-se mais seco (tipo semi-árido quente), ocasionando o surgimento da caatinga, que é uma vegetação xerófita.

Nas regiões Sudeste e Sul, o relevo torna-se bem mais acidentado, com a presença de vigorosas escarpas litorâneas e sublitorâneas, mais conhecidas pelos nomes de Serra do Mar, Serra da Mantiqueira, Serra do Paranapiacaba e Serra Geral, todas voltadas para leste ou sudeste. A poucas dezenas de quilômetros da costa, essas escarpas se elevam a centenas de metros de altitude, proporcionando um acentuado contraste altimétrico entre as baixadas litorâneas, o Vale do Paraíba e as íngremes encostas dessas serranias. Os ventos alíseos de sudeste, ao abordarem essas serras, proporcionam-lhes densos nevoeiros e abundantes chuvas orográficas, que se precipitam nas suas vertentes de barlavento. Tais chuvas e nevoeiros conferem a essas de encosta um caráter de florestas ombrófilas perenifólias. No reverso das escarpas, as precipitações diminuem bastante e as matas passam a ter feições de florestas mesófilas subcaducifólias. Além disso, o relevo serrano e a gradação das altitudes, como se fosse um enorme anfiteatro, favorecem uma melhor distribuição da luz solar pelo dossel da mata, e, 
certamente por isso, as árvores emergentes da Mata Atlântica não chegam a ser tão altas como as da Floresta Amazônica, onde o relevo é predominantemente plano, ou ligeiramente ondulado.

Em alguns trechos serranos mais elevados, como no Maciço do Caparaó, na Serra dos Órgãos e no Maciço do Itatiaia, a partir de certo limite altitudinal, ocorrem as matas de altitude ou matas nebulares, também chamadas por Rizzini (1979) de "floresta tropical montana". Essas matas constituem um terceiro fácies da Mata Atlântica, sempre onde o relevo se apresenta mais montanhosos e escarpado. Sua ocorrência verifica-se no alto das escarpas e das serras, com altitudes entre 500 a 1700 metros, aproximadamente, conforme as latitudes e o grau de exposição. Nessas altitudes, densos nevoeiros ocorrem com muita freqüência, concorrendo para o aumento da umidade e a diminuição da luminosidade; somam-se a esses fatores as baixas temperaturas e os ventos. Essas matas são constituídas por árvores finas e baixas, de até oito metros de altura, não sendo raras as moitas de bambus finos e flexíveis (criciuma). Devido à umidade e ao frio, elas apresentam numerosas pteridófitas, musgos e líquenes. As matas nebulares ou de altitude, em certos lugares, podem ter a presença do pinheirodo-paraná (Araucaria angustifolia), que chega a formar associações relativamente densas. Acima de 1400 ou de 1700 metros de altitude, essas formações florestais são substituídas pelos "campos de altitude".

Desde a cidade do Rio de Janeiro até Florianópolis, o litoral é acompanhado de perto por inúmeras ilhas esparsas, de aspecto montanhoso, geomorfologicamente ligadas ao relevo continental. Todas elas estão recobertas pela Mata Atlântica, em razoável estado de preservação, exceto a Ilha de Santa Catarina, que abriga a capital do estado homônimo, tendo a mesma sofrido intensa devastação desde o século XVI. Coladas ao litoral, as ilhas sedimentares, alongadas e baixas, são restingas em vários estágios de formação, ocupadas por outros tipos de vegetação. Transpostas as serras atlânticas,

em direção ao interior, sua penetração não é muito ampla e seu limite pode ser determinado pelas alterações na composição florística e pela mudança da dinâmica dos fenômenos fenológicos da floresta. A formação perenifólia dá lugar a uma formação semi-decídua que apresenta um padrão típico de queda de folhas nos meses de baixa precipitação. Considerando essas diferenças de composição e dinâmica fica evidente que é errado se utilizar a denominação Mata Atlântica para as formações florestais que ocorrem no interior dos estados de São Paulo, Mato Grosso do Sul, Paraná, Santa Catarina e Rio Grande do Sul. Pelas mesmas razões as matas com araucária que ocorrem nesses últimos três estados, também não devem ser consideradas como parte da Mata Atlântica (JOLY; LEITÃO FILHO; SILVA, 1991, p. 102). 
Nesta relação de estados da Federação, poderíamos incluir, também, o Estado de Minas Gerais.

Para oeste, para além do Rio Paraná, no Estado de Mato Grosso do Sul, a floresta tropical atlântica estendia-se como uma faixa de contornos irregulares, como se fosse uma larga floresta galeria do grande rio platino.

\section{ESTRUTURA E COMPOSIÇÃO FLORÍSTICA}

A estrutura da Mata Atlântica varia conforme os seus subtipos. A floresta ombrófila ou higrófila, perenifólia, mantém sua folhagem em caráter permanente, promovendo uma intensa evapotranspiração, com uma incidência de luz solar enfraquecida nos seus estratos inferiores. Já a floresta mesófila subcaducifólia, ou semidecídua, e a floresta tropófila, tem comportamento diferente, pois perdem uma parte considerável de sua folhagem durante o período de estiagem, reduzindo a transpiração e permitindo a penetração da luz solar no seu interior com mais facilidade; nela a competição pela luz é menor, a floresta fica mais baixa e há menor número de epífitas.

Sua estrutura horizontal ostenta forte densidade, um caráter de mata fechada, justamente pelo fato de haver grande número de espécies vegetais concentradas num pequeno espaço. Soma-se a isso a exuberância permanente da vegetação, verde e viçosa o ano todo, característica atribuída à ausência de um período de repouso vegetativo anual, fato inerente às regiões tropicais úmidas e superúmidas. Nenhum período de frio rigoroso, nenhuma estação seca prolongada vem alterar a regularidade climática dominante e nem perturbar a continuidade dos processos vegetativos na comunidade florestal.

Tal como a Floresta Amazônica, a floresta higrófila apresenta a seguinte estratificação (estrutura vertical): a) emergentes - árvores mais altas e espaçadas entre si; b) dossel ou abóbada foliar - camada de árvores cujas copas se tocam e se entrelaçam; c) sub-bosque - estrato de árvores mais baixas e de árvores novas em crescimento, que se desenvolve sob o dossel; d) estrato rasteiro - camada superficial de plantas herbáceas, possuidoras de folhas grandes, largas e tenras. As lianas e as epífitas são formas de vida que se agregam aos estratos médio e superior, pelo fato de que estão competindo pela luz. Tudo nessa folhagem favorece o livre escoamento das águas pluviais: as árvores possuem folhas acuminadas, enquanto as folhas das plantas rasteiras são grandes, lisas e impermeáveis, pelas quais as águas 
escorrem sem se acumular. Já nos recantos sombrios e úmidos, onde a luz chega com dificuldade, proliferam os musgos, líquenes, hepáticas e fungos.

O chão da floresta, em geral muito úmido, é recoberto por uma espessa serapilheira ou manta, constantemente reabastecida pelos troncos e galhos caídos, pelas folhas caducas e outros detritos orgânicos. Todo esse material residual, que constitui o húmus bruto, é logo processado pelos seres saprófitos ou decompositores.

Sua composição florística é extremamente variada, com grande biodiversidade, tanto em termos taxonômicos como em termos de formas de vida e de tamanho dos vegetais. Predominam nessa formação florestal, dentre as árvores, membros das famílias das leguminosas, bignoniáceas, lauráceas, meliáceas, mirtáceas, apocináceas, rutáceas, entre tantas outras. No estrato rasteiro, são mais freqüentes as plantas herbáceas das famílias das musáceas (helicônias), marantáceas, zingiberáceas, begoniáceas e algumas espécies de bromeliáceas terrestres. No grupo das epífitas ocorrem numerosas espécies das famílias das aráceas (filodendros), bromeliáceas e orquidáceas, que muito contribuem para a ornamentação interna da mata. Determinadas plantas destacam-se, ora pelo seu porte avantajado, ora pela sua beleza ou valor econômico, como as figueiras (gên. Ficus e Urostigma), a juçara (Euterpe edulis), o feto arborescente ou samambaiaçu (Cyathea schanschin) e a minúscula bromeliácea pendente, conhecida por "barba-de-velho" (Tillandsia usneoides), muito comum em algumas árvores da floresta subtropical, na condição de epífita.

Grande parte dos autores que escreveram sobre a Mata Atlântica avaliou a altura média de suas árvores (dossel) em 25 a 30 metros, porém, esses valores abaixam na "mata seca", na "mata-de-cipó" (15 a 20 metros) e nas matas de altitude ou nebulares (oito a dez metros).

Mata primária e mata secundária. São dois aspectos evolutivos da mesma formação florestal, sendo que uma derivou da outra, em conseqüência de devastação antiga. Tivemos oportunidade de observar esses dois aspectos da mata no Parque Estadual Intervales, no município de Ribeirão Grande (SP), com o monitoramento de guias locais. O referido parque tem 38000 hectares de área, com vegetação florestal preservada e representativa da Mata Atlântica, na Serra de Paranapiacaba.

A mata primária é a mata original ou primitiva, na sua fase de clímax, aquilo que é popularmente conhecido por "mata virgem", pelo fato de nunca ter sido queimada ou derrubada, para qualquer finalidade. $\mathrm{O}$ ambiente natural para as duas formações é exatamente o mesmo, em que pese a interferência do homem ter acarretado 
alterações na sua composição florística. A mata primária caracteriza-se pela sua maior biodiversidade, pelo maior porte de suas árvores, algumas bem-velhas, enredadas de lianas e com numerosas epífitas. Assim, "quanto mais densa a mata, tanto mais desfavoráveis as condições de luz no seu interior, e tanto mais freqüentes são as epífitas e as lianas" (WETTSTEIN, 1970, p. 36). É nela que se encontram as madeiras de lei, de lenho duro e de coloração variada.

A mata secundária, às vezes chamada de "capoeira", é mais aberta, tem árvores mais baixas e mais finas, onde as lianas são raras e a penetração da luz solar é facilitada. Neste tipo de mata são freqüentes as plantas heliófitas e oportunistas, como as embaúbas (Cecropia sp), a quaresmeira (Tibouchina granulosa), o manacá-da-serra (Tibouchina mutabilis), a cássia-alelúia (Cassia multijuga) e numerosas espécies de palmeiras. Certamente, elas fazem parte de um estágio evolutivo da floresta (disclímax), até porque não são árvores de grande porte e nem produzem madeiras duras. Existem matas secundárias em vários estágios de regeneração.

\section{O AGRESTE E OS “BREJOS”. OS CAPÕES}

Na Região Nordeste, entre a Zona da Mata e o Sertão, interpõe-se uma pequena faixa de transição, chamada Agreste. Referindo-se a ela, Andrade (1986, p. 31) assim se expressou:

Às vezes ele (Agreste) é bem-característico em seus aspectos, mas em outras ocasiões pode ser confundido com a Mata em seus trechos mais úmidos e com o Sertão nos mais secos. Áreas há do Agreste [...] que primitivamente eram cobertas pela Mata Atlântica e que hoje são classificadas como agrestinas, devido mais ao tipo de ocupação humana e de uso da terra do que às condições naturais.

No passado, o Agreste era um tipo de vegetação misto, com trechos de mata e de caatinga entremeados, com a coexistência de floras típicas de uma e de outra formação; atualmente, depois de muita devastação, o Agreste é considerado uma zona ou subregião do Nordeste, posicionada na vertente oriental da Borborema, nos estados do Rio Grande do Norte, Paraíba, Pernambuco e Alagoas. Na opinião de alguns autores, o Agreste é um antigo trecho de Mata Atlântica em processo de degradação, natural ou antrópica.

Os "brejos" são ocorrências de mata higrófila, envolvidas pelas caatingas, beneficiando-se de condições climáticas favoráveis, impostas pelo relevo regional ou local. Nas áreas atingidas pelas secas prolongadas, enquanto as caatingas ocupam 
extensas depressões semi-áridas, os "brejos" instalam-se onde o relevo favorece as precipitações, ou seja, nas escarpas das chapadas, nas serras e nos vales úmidos orientados no sentido NO-SE, onde não incidem as secas e onde os córregos e ribeirões mantém suas águas correntes. Nesses lugares as chuvas caem com mais regularidade, abastecendo os cursos d'água e promovendo a formação de solos mais espessos e mais férteis. A altitude concorre para a diminuição da temperatura, além de atenuar a intensidade da evaporação, e à noite a condensação aumenta, produzindo nuvens e nevoeiros. Todos os "brejos" têm os mesmos aspectos em comum, porém, aqueles do Agreste são menores e estão ilhados pela vegetação peculiar a esta zona, enquanto que os "brejos" do Sertão são vastos, mas às vezes minúsculos, estando sempre cercados pelas caatingas.

É no Estado do Ceará que se localizam os maiores "brejos" do Sertão, e do Nordeste, como o do Cariri (Chapada do Araripe), o da Chapada do Ibiapaba e o da Serra de Baturité. Na Paraíba, o destaque é para o único e grande Brejo Paraibano, no Agreste, enquanto que em Pernambuco verifica-se a existência de um grande número de pequenos "brejos", que costumam ser agrupados num "Complexo de brejos pernambucanos".

Segundo Andrade (1986, p. 36), essas matas residuais nordestinas apresentam os seguintes tipos, conforme a sua posição no relevo:

- brejos de altitude e de exposição (Agreste, Sertão);

- brejos de pé-de-serra (Agreste, Sertão);

- brejos de vale (Agreste);

- brejos ciliares (Agreste).

Qualquer que seja o seu tipo e as suas dimensões, essas matas ilhadas no Agreste e no Sertão representam formações vegetais relíquias, ou relictos, remanescentes de climas mais úmidos do passado. Isso significa que esses "brejos" são o que restou de uma mata tropical higrófila, que se estendia desde o litoral oriental do Nordeste até às chapadas do oeste e do sul do Ceará.

Já no Rio Grande do Sul, a paisagem campestre de suas "coxilhas" é, com freqüência, pontilhada por capões, que são pequenos trechos de matas mistas, de contornos grosseiramente circulares. Desde remotos tempos, os indígenas os chamavam “caá-apoam" (matas redondas ou circulares), que os colonizadores aportuguesaram para capões, termo que até hoje perdura. Existem capões de tamanhos variados, alguns com poucas árvores agrupadas, outros com vários hectares de extensão, sempre recobrindo 
as encostas das colinas, próximos a mananciais ou a pequenos cursos d'água (arroios). Nessas formações florestais isoladas, "é na parte central que se encontram as árvores de maior porte e a estrutura vertical típica de uma floresta"; em altitudes acima de 500 metros sobressai a Araucaria angustifólia.

Na sua monografia, Marchiori (2004, p. 53-54) esclarece que,

Nestes capões, a flora alia elementos antárticos, como o pinheiro-brasileiro (Araucaria angustifolia), com espécies andinas, holárticas e imigradas das florestas Atlântica e Estacional. Por sua distribuição fragmentária, os capões da Floresta Mista depõem favoravelmente à interpretação relitual dessa vegetação, imigrada a partir das encostas da Serra Geral, atualmente ocupadas por florestas latifoliadas (Estacional e Atlântica), num processo iniciado ao final do Pleistoceno, com o aquecimento e umidificação do clima.

Como se trata de pequenas florestas residuais mistas, os capões diferem floristicamente uns dos outros, conforme a sua localização no estado gaúcho. Nesta lógica geográfica, os capões que mais se identificam com a Mata Atlântica, em sua composição e estrutura, são aqueles situados no setor oriental do estado.

\section{FLORESTAS GALERIAS E MATAS CILIARES}

Entre a Mata Atlântica e a Floresta Amazônica estende-se uma larga faixa diagonal de formações vegetais abertas e complexas, representada ela caatinga (Nordeste), pelo Cerrado (Centro-Oeste e Sudeste) e pela vegetação variada do Pantanal Mato-Grossense. Essa diagonal fitogeográfica tem orientação geral NE-SO, sendo prolongada em território boliviano, paraguaio e argentino pela vegetação do Chaco. Todas essas formações vegetais estão subordinadas a climas quentes menos chuvosos quando comparadas às formações florestais amazônica e atlântica.

Nessa faixa diagonal de formações abertas é que se situam as florestas galerias e as matas ciliares, as quais, fugindo aos padrões fitogeográficos regionais, acompanham os cursos d'água, grandes ou pequenos, aproveitando a umidade dos solos justafluviais. São fragmentos lineares de matas, interrompendo a monotonia da caatinga ou do cerrado. As matas ciliares ocorrem, também, nos "Campos Gerais" da Região Sul, porém, geralmente, estão relacionadas com a Floresta de Araucárias. É essa umidade local dos solos de beira-rio que explica tão radical mudança da vegetação, em tão curta distância, em áreas climaticamente homogêneas; nessas condições, nada muda no clima, porém, muda nos solos. Segundo Oliveira Filho; Ratter (2000, p. 74), 
o corredor seco de formações abertas foi considerado por muitos autores como uma importante barreira para a migração de espécies entre as duas grandes regiões florestais da América do Sul, explicando portanto muito das diferenças florestais entre elas. Por outro lado, os padrões de distribuição disjunta de um considerável número de espécies que ocorrem nas Florestas Atlântica e Amazônica sugerem a existência de ligações florestais no passado.

Alguns autores julgam ter havido duas "pontes", ou faixas de ligação, entre as duas grandes florestas sul-americanas: uma no Nordeste e outra mais ao sul, no sentido NO-SE, provavelmente entre os estados de Mato Grosso e Minas Gerais. Essas supostas "pontes" seriam o meio de intercâmbio florístico entre a Amazônica e a floresta tropical atlântica. As evidências prováveis, que alicerçam essas interpretações, são as matas residuais do Nordeste ("brejos") e as florestas mesófilas e tropófilas do Brasil Central ("matas secas" e outras). Fica evidente que o cerrado e as florestas compartilham importantes espaços nessa parte do país. Seguramente, as florestas galerias funcionam, até certo ponto, como matas residuais a testemunhar o recuo das matas outrora mais extensas. $\mathrm{O}$ avanço ou o recuo, tanto das matas como do cerrado, são conseqüências das oscilações paleoclimáticas recentes (fins do Pleistoceno, Holoceno).

Em caráter preliminar, pode-se considerar a composição florística das matas ciliares do Brasil Central um tanto heterogênea, com elementos da flora amazônica, elementos da flora atlântica e elementos autóctones ou endêmicos. Geograficamente, é importante considerar que as florestas galerias seguem rios de diferentes bacias hidrográficas, que fazem ligação com diferentes formações florestais; tal fato deve ser levado em conta nos estudos botânicos, relativos a levantamentos florísticos, das inúmeras matas de beira-rio.

\section{SOBREVIVÊNCIAS PALEOCLIMÁTICAS. ENCLAVES}

No seu artigo "Jardims suspensos do Sertão", Cavalcante (2005) estudou a situação dos "brejos" cearenses, e em especial a mata residual da Serra de Baturité, ao sul de Fortaleza. Esse pesquisador constatou que há uma grande afinidade florística entre a referida mata e a Mata Atlântica, pois, muitos gêneros e espécies botânicos ocorrem nas duas formações, e lembra, também, que "há árvores comuns entre Baturité e a região amazônica". No reino animal a situação é semelhante, porque há espécies comuns à Floresta Amazônica e à mata de Baturité, referidas pelo autor. Com base nessas evidências biogeográficas, Cavalcante (2005, p. 71) questiona: "teria existido alguma conexão florística concreta dos enclaves cearenses com a floresta 
amazônica? E os enclaves cearenses seriam restos de uma antiga parte que remotamente unira a Mata Atlântica às matas da Amazônia?" Somente pesquisas futuras bemfundamentadas, e em número satisfatório, trariam as respostas.

Entretanto, essas evidências não são tão novas, pois já foi constatada, anos atrás, uma correspondência florística entre a chamada "Hiléia Baiana" e a Floresta Amazônica. Muitas espécies amazônicas ocorrem na Hiléia Baiana, inclusive o açaí (Euterpe oleracea). Entre as duas formações florestais coloca-se a caatinga, com estrutura e composição florística muito diferentes.

Segundo Cavalcante (2005), o Sertão nordestino teria sido coberto, extensivamente, por densa floresta tropical durante todo o período Terciário. Todavia, no transcorrer do Pleistoceno, a sucessão de quatro (ou cinco) glaciações e de períodos interglaciários, com suas severas seqüelas climáticas, teria rompido a continuidade dessa grande floresta, compartimentando-a em vários trechos isolados. Na área do atual Sertão nordestino - por alguns chamado de "Semi-Árido" - desenvolveu-se a caatinga, com sua flora xerófita típica. E, isoladamente, como ilhas no meio da caatinga, ocorrem os "brejos", na condição de formações florestais remanescentes, como enclaves de matas.

A caatinga, sendo uma vegetação xerófita, avançava e dominava os espaços baixos do relevo, particularmente nas fases glaciárias (do hemisfério Norte), quando então o clima se tornava árido. Após a glaciação Wurm-Wisconsin, nos últimos dez ou doze milhões de anos, com a instalação do clima semi-árido quente na Região Nordeste, a floresta tropical úmida não conseguiu reconquistar seus espaços perdidos. Então, o que restou foram as pequenas matas ilhadas pela caatinga ("brejos"), posicionadas em lugares mais elevados, onde a pluviosidade seria suficiente para a sua sobrevivência. Cavalcante (2005) afirma que, em todo o Sertão nordestino, existem pouco mais de vinte matas residuais, na condição de enclaves. Com certeza, esses enclaves biogeográficos no domínio da caatinga são sobrevivências paleoclimáticas, pois, se o clima mudou, não mudaram essas pequenas formações vegetais. Assim, os "brejos" de hoje são heranças, ou sobrevivências, de climas mais úmidos do passado geológico recente.

\section{ASPECTOS GEOMORFOLÓGICOS}

Geomorfologicamente, a Mata Atlântica recobre um relevo muito diversificado, desde os tabuleiros terciários do Nordeste até as grandes escarpas basálticas da Serra 
Geral, em Santa Catarina e no Rio Grande do Sul. Nos tempos atuais, é nas serras da Região Sudeste e do Paraná que ela se apresenta mais exuberante. Seus solos são, também, muito variados, predominando os latossolos amarelos (oxissolos) e os solos podzólicos vermelho-amarelados (ultissolos), sobrepondo-se a regolitos muito espessos. Solos dessa natureza foram produzidos por intemperismo químico muito intenso e lixiviação contínua, seguidos de uma pedogênese ativa sob cobertura florestal.

Nos regolitos dos morros, colinas e terraços, os geomorfólogos tem observado e registrado a existência de camadas de "solos" superpostos, ou seja, de terrenos intemperizados de natureza diversa a recobrir as rochas matrizes: são elúvios, colúvios e linhas de pedras (stone lines), irregularmente superpostos, que indicam diferentes fases paleoclimáticas do Quaternário. Os elúvios são o produto direto da decomposição das rochas no local, conservando sua estrutura original, e que, ao se deslocarem ladeira abaixo, transformam-se em colúvios; gradativamente, elúvios e colúvios evoluem e, com a colonização vegetal e a incorporação da matéria orgânica, passam à condição de solos. Os colúvios, de sedimentos finos, argilo-siltosos, indicam fases de climas quentes e úmidos; já as stone lines - leitos de cascalhos subangulosos inumados (enterrados) - situados a poucos decímetros abaixo da superfície, indicam paleopavimentos detríticos, representativos de climas áridos e semi-áridos do passado.

A alternância vertical de colúvios e de stone lines, num regolito, indica oscilações paleoclimáticas, as quais teriam influenciado os antigos avanços e recuos da floresta tropical atlântica no Planalto Brasileiro. Os períodos úmidos favoreceriam a expansão da floresta higrófila, com a formação de colúvios nas vertentes; os períodos de aridez ou de semi-aridez forçariam a retração da floresta, quando então se produziriam os pavimentos detríticos ou cascalheiras. Disso se conclui que a estrutura de um regolito passa a ser a chave para uma correta interpretação de paleoclimas do Plioceno e do Quaternário, e da dinâmica pretérita da vegetação que o reveste.

Assimilando todos esses processos e identificando quadros de paisagens naturais pelo país, Ab'Saber (1965-1966), elaborou sua consagrada classificação de domínios morfoclimáticos do Brasil. Nessa classificação, o autor incluiu a Mata Atlântica no domínio dos "mares de morros" - expressão cunhada pelo geógrafo francês Pierre Deffontaines, em 1939. Isso significa que o relevo subjacente à Mata Atlântica apresenta formas arredondadas, com vertentes convexas e policonvexas generalizadas. O arredondamento ou "mamelonização" das montanhas, morros, colinas e terraços seria produzido por um conjunto de processos morfoclimáticos, subordinados a climas 
tropicais úmidos, atuando integradamente, como a decomposição química e a reptação das rochas e dos solos, e, eventualmente, avalanches de detritos nas escarpas e nas encostas mais altas e abruptas.

Foram esses processos que geraram os colúvios, tão comuns nas florestas tropicais úmidas. Uma vez formado um regolito espesso sobre os morros e as escarpas, e sendo saturado com frequiência pelas chuvas, essa massa detrítica instável desce ao longo das vertentes, lentamente, movida pela força da gravidade, até criar formas de relevo arredondadas. Dessa maneira formaram-se os morros do tipo "meia laranja" que, repetidos ao infinito na paisagem de uma região, constituem os "mares de morros"; e também outras formas de relevo típicas desse domínio, como os domos de esfoliação e os "pontões" ou "pães de açúcar", tão comuns em alguns trechos dos estados do Rio de Janeiro e do Espírito Santo. Todos esses processos atuaram (e atuam) durante Quaternário, na sua fase pós- Wurm. Climas quentes e úmidos, vegetação florestal biodiversa e densa, solos espessos e argilosos, morros e colinas arredondados e uma rede de drenagem dendrítica e perene compõem esse quadro fisiográfico do domínio dos "mares de morros". Nas áreas sedimentares litorâneas, de relevo tabuliforme, não se formaram os "mares de morros", embora tenha ocorrido o arredondamento das vertentes.

\section{DEVASTAÇÃO}

A devastação da Mata Atlântica é secular e corre paralela à história econômica do Brasil. A cada ciclo econômico correspondeu o desaparecimento de mais uma grande parcela da mata ao longo de sua extensão total. Sua devastação remonta, pois, ao início da colonização, e recrudesceu nos séculos subseqüentes, movida pelos interesses econômicos ligados sobretudo às monoculturas canavieira e cafeeira. O próprio povoamento de uma região requer desmatamento. A mata original, aos poucos, foi cedendo espaço às lavouras comerciais, que acabaram avassalando as outras culturas.

A exploração madeireira começou com a procura do pau-brasil (Caesalpinia echinata), no litoral nordestino, mormente na Bahia. Prado Júnior (1959, p. 26), em História Econômica do Brasil, afirmou que "foi rápida a decadência da exploração do pau-brasil. Em alguns decênios esgotara-se o melhor das matas costeiras que continham a preciosa árvore, e o negócio perdeu seu interesse". Lendo o brasilianista Dean, a impressão que fica é outra, pois, nos fins do século XVI e no século XVII houve muito comércio dessa madeira, praticado por mercadores portugueses, e também 
clandestinamente, por franceses, espanhóis e ingleses.

A cultura canavieira, que se expandiu a partir do século XVI no Nordeste, sacrificou a mata original não apenas pela sua destruição sumária para o plantio dos canaviais, mas também para fazer uso de suas madeiras de lei. Essas madeiras nobres foram fartamente utilizadas na construção das casas-grandes, das capelas, das senzalas, dos sobrados urbanos, das pontes, dos carros de boi, do mobiliário, etc. Portanto, a civilização do açúcar fez-se às custas do sacrifício da mata nativa.

Parte considerável dessas madeiras foi remetida para Portugal, conforme atesta Freyre (1961, p. 53-54):

o que Portugal retirou de madeira no Nordeste do Brasil, para levantar ou reparar seus conventos, suas igrejas, seus palácios, toda a sua arquitetura voluptuosa, para construir seus barcos e seus navios, forma um capítulo de exploração econômica do Brasil pela Metrópole. [...] Quase não há edifício nobre em Portugal que não tenha um pedaço de mata virgem do Brasil [...].

Para a posteridade, da faixa florestal nordestina apenas restou o topônimo "Zona da Mata", regionalmente consagrado na geografia brasileira.

Abrangendo a parte central do Estado de Minas Gerais, o Ciclo da Mineração também teve sua quota de participação no processo de desmatamento, conforme nos esclarece Dean (2004, cap. 5) em seu livro. O historiador mineiro Lima Júnior (1978, p. 117), em A Capitania de Minas Gerais, afirmou que

os operários europeus encontraram no jacarandá e no cedro, sobretudo, o material por excelência para o mobiliário opulento que encheu as casas mineiras do século de nossa formação (século XVIII) em tanta abundância que ainda hoje, não obstante o comércio intenso que disso se fez e ainda se faz, pode ser encontrado in loco em alguns lugares.

Também nesse estado o que restou da antiga mata foi o topônimo "Zona da Mata mineira", já densamente povoada.

No norte do Estado do Espírito Santo, mais ou menos entre 1950 e 1970, o jacarandá-da-baía (Dalbergia nigra) - a mais nobre das madeiras atlânticas - foi intensamente explorado, provocando a devastação da mata nessa área, com graves conseqüências ambientais.

A lavoura cacaueira, estabelecida entre Nilo Peçanha (BA) e Linhares (ES), desde meados do século XVIII, danificou menos a mata, pois, sendo o cacaueiro uma árvore baixa, ela faz parte do sub-bosque, dando-se bem à sombra das árvores mais altas, contanto que as condições climáticas lhe sejam favoráveis. Em alguns casos a 
mata foi derrubada, mas em outros, processou-se o "cabrocamento", uma prática que consiste na roçada do sub-bosque para o plantio do cacaueiro à sombra das grandes árvores. Neste caso, conservam-se os estratos superiores da mata. Deve-se notar que os proprietários de fazendas de cacau, sendo absenteístas, mantém casas de moradia pequenas e simples nas suas propriedades, não se servindo abusivamente das madeiras.

Na Região Sudeste e no Norte do Paraná, as matas foram devastadas para dar lugar às lavouras de café. O período imperial e escravocrata marcou a fase das grandes fazendas aristocráticas, presentes sobretudo no Vale do Paraíba, na Zona da Mata mineira, no Sul de Minas e na Baixa Mogiana (SP). No Estado do Espírito Santo tiveram menor expressão. Tal como no Nordeste, as madeiras nobres foram utilizadas na construção de casarões suntuosos, sedes de fazendas, capelas, tulhas, pontes, além de igrejas e sobrados nas cidades.

Nos estados da Região Sul, revestidos pela Mata Atlântica - exceto o Norte do Paraná - a presença de imigrantes europeus e seus descendentes criou um regime de pequenas propriedades rurais, mas que também resultou em devastação. Italianos, alemães, poloneses, holandeses e ucranianos recorreram às queimadas para limpar o terreno e plantar seus roçados, seus vinhedos, e extrair madeiras e lenha. Nos dias atuais, a chamada "Serra Gaúcha" ostenta apenas matas secundárias pobres, que não contribuem em nada para a beleza de suas paisagens. Pequenos trechos de mata nativa preservada ficam restritos aos penhascos dos canyons da Serra Geral, em lugares de difícil acesso.

A partir da segunda metade do século XX, com o aumento da população e o êxodo rural crescente, a urbanização tomou forte impulso no Brasil. Todas as cidades cresceram rapidamente e as zonas metropolitanas se agigantaram, aumentando progressivamente as áreas urbanizadas. Para ligar as cidades entre si e as redes urbanas cada vez mais densas e integradas, houve a necessidade de se abrir várias rodovias e estradas vicinais, muitas delas cortando trechos de matas, em áreas muito chuvosas e de relevo acidentado. A expansão das cidades e das rodovias que as ligam causou, localmente, impactos ambientais de certa gravidade.

\section{IMPACTOS AMBIENTAIS}

Cubatão e Piaçagüera são dois municípios situados na Baixada Santista, bem próximos do sopé da Serra do Mar. Nesses municípios, o processo de industrialização iniciou-se na década de 1950, prolongando-se nas duas décadas seguintes. Formou-se aí 
um poderoso complexo industrial, tendo como indústrias de base a Usina Hidroelétrica Henry Borden, a Cosipa (Companhia Siderúrgica Paulista) e a Refinaria Presidente Bernardes, em torno das quais instalaram-se mais de 20 indústrias associadas, consumidoras de suas matérias-primas. Nesse complexo destaca-se o Pólo Petroquímico de Cubatão, liderado pela referida refinaria.

Perto de São Paulo e do porto de Santos, a localização dessas indústrias parecia geograficamente correta, porém, a poucos quilômetros dela ergue-se a Serra do Mar localmente conhecida por Serra de Cubatão ou Serra de Paranapiacaba - com 700 a 800 metros de altitude, revestida por densa mata tropical. Essa serra, voltada para sudeste, funciona como um anteparo natural aos ventos úmidos de origem marinha, que propicia a formação de nevoeiros e a precipitação de abundantes chuvas orográficas, fenômenos mantenedores dessa mata. As indústrias aí instaladas passaram a lançar na atmosfera seus gases tóxicos e seus resíduos sólidos (poeiras), em grande quantidade, contaminando seriamente o ar da planície e da serra próxima.

Analisando a situação, Ab'Saber (1982, p. 21) afirmou que

\begin{abstract}
as conseqüências disso tudo é que o forte volume de partículas e de gases, elevados pelo ar quente e posteriormente despejado pelas chuvas orográficas, afeta profundamente a cobertura vegetal das encostas e os altos da serra de Paranapiacaba, tendo sido responsável, em certas fases de máximo envenenamento do ar, pelo generalizado fenecimento da vegetação arbórea existente desde a base ao topo e até um pouco além da cimeira da Serra de Paranapiacaba, somando parcialmente a poluição da baixada com a provocada pelos próprios focos planálticos de poluição.
\end{abstract}

As precipitações fortemente contaminadas por gases tóxicos, com efeitos nocivos à vegetação e à sua fauna, há algum tempo passaram a ser conhecidas por chuvas ácidas. Esse tipo de precipitação é contaminado pela formação de ácido sulfúrico e ácido nítrico, derivados de óxidos de enxofre liberados pelas indústrias petroquímicas, usinas termoelétricas é outras fontes poluidoras. Esses ácidos reagem com o vapor d'água e outros gases atmosféricos, produzindo as chuvas ácidas. Segundo Branco (1984, p. 79), a acidez dessas chuvas apresenta um pH abaixo de 5,6, podendo chegar a dois, valor extremamente baixo. Comprovadamente, as chuvas ácidas podem causar a morte das árvores e a contaminação dos solos e das águas.

Na opinião de Branco (1984, p. 79),

um dos efeitos mais notórios da poluição do ar é a morte das árvores, especialmente as de maior porte. Esse efeito pode ser decorrente diretamente da ação de poeiras ou de gases tóxicos, tais como o NO ou o SOproduzidos em Cubatão pelas indústrias que queimam carvão ou petróleo ou de fluoretos, produzidos por indústrias de cimento que empregam 
subprodutos da COSIPA, ou mesmo por poeiras "inertes" de diversas espécies.

O despojamento da folhagem das árvores causa outros problemas ambientais, como os bruscos deslizamentos de terra e avalanches de detritos, de consequiências desastrosas. Um fato já observado é o desaparecimento da fauna local, especialmente dos animais arborícolas, que perdem seus habitats, seus refúgios e suas fontes de alimentação.

Outro fato marcante, de natureza geológica e geomorfológica, foi o desencadeamento de avalanches de detritos e corridas de terra, que afetaram as encostas da Serra do Mar, nas proximidades de Caraguatatuba, no dia 18 de março de 1967. As condições geológicas e geomorfológicas da área em apreço, somadas aos elevados índices pluviométricos do mês de março daquele ano, conspiraram para o desencadeamento desses gigantescos movimentos de massa, que por muito pouco não teriam arrasado a cidade de Caraguatatuba. Os morros e os esporões dessa região, antes cobertos extensivamente pela mata, ficaram escalavrados por inúmeras marcas dos deslizamentos de terra, que corroeram suas encostas por grandes extensões. Nesse episódio geológico, muitas árvores e outros vegetais desceram de cambulhada pelas ravinas, entulhando as partes baixas dos vales. Fenômeno semelhante ocorreu na Serra das Araras (RJ), no ano de 1948.

Em passado não muito distante, cidades importantes como Petrópolis, Niterói, Campos do Jordão e Santos tiveram casos de corridas de terra e deslizamentos de encostas, que ocasionaram grandes estragos, danificando principalmente as moradias das populações mais pobres. São casos pontuais de agressão à natureza, de rompimento do seu equilíbrio natural, com conseqüências ambientais lamentáveis.

Especialmente os casos de Cubatão-Piaçagüera, de Caraguatatuba e da Serra das Araras são lembrados como os casos mais espetaculares de impactos ambientais devastadores, que atingiram importantes trechos da Mata Attântica em áreas serranas.

Impactos ambientais, com graus variáveis de gravidade, têm ocorrido em vários pontos, e em várias ocasiões, no domínio das matas costeiras. Além das indústrias poluidoras, muitas outras causas concorreram para a degradação da mata e do meio ambiente do qual faz parte, como: práticas agrícolas empíricas (culturas de subsistência, bananicultura), extração de pedras para construção e pavimentação, mineração (calcário, caulim, galena, carvão-de-pedra), desmonte de sambaquis, construção de rodovias e abertura de estradas de terra, construção de barragens em usinas hidroelétricas, 
exploração imobiliária desordenada e, em menor escala, extração de madeiras, de lenha e de palmito.

\section{PRESERVAÇÃO}

A efetiva preservação de áreas naturais só se torna viável mediante a intervenção dos poderes públicos, sobretudo no âmbito federal. Com essa finalidade foram implantados, por meio de decretos-leis, diversos parques nacionais, espalhados pelo país. O primeiro a ser criado foi o Parque Nacional do Itatiaia, em 1937, que tem prestado relevantes serviços às ciências biológicas e às geociências do Brasil, e até do exterior. A criação desses parques vem sendo feita ao longo dos anos, sendo as suas áreas, individualmente, muito desproporcionais às dimensões do território brasileiro. Uma vez instalados, esses parques passam por muitas dificuldades administrativas, financeiras e de fiscalização.

Os parques nacionais são áreas destinadas à preservação do meio ambiente natural, dos seus recursos e das paisagens que contenham reconhecida importância ecológica, geológica, arqueológica, histórica e paisagística (belezas naturais). Além do seu caráter conservacionista, os parques nacionais prestam-se a outras finalidades, como campos de pesquisas, de turismo ecológico e de lazer.

Ao serem criados, muitos desses parques já teriam perdido, no todo ou em parte, a sua cobertura vegetal primitiva, devido à exploração predatória do homem. Nessa situação acha-se o Parque Nacional do Caparaó, no qual a maioria das comunidades vegetais originais foi degradada, e acha-se em fase de lenta recuperação. No passado, essa região montanhosa e de belas paisagens era de pleno domínio da Mata Atlântica, e hoje é ocupada por capoeiras ralas, matagais e campos de altitude muito pobres.

Até a presente data (2008), são doze os parques nacionais incluídos nos domínios da Mata Atlântica (cf. Parques Nacionais: Brasil, Ibama):

1. P. N. do Monte Pascoal (BA): 1961 25.500 ha

2. P. N. do Descobrimento (BA): 2000 (?) ha

3. P. N. do Caparaó (ES-MG): 1961 25.000 ha

4. P. N. da Serra dos Órgãos (RJ): 1939. 11.000 ha

5. P. N. do Itatiaia (RJ-MG): 1937 30.000 ha

6. P. N. da Tijuca (RJ): 1961 .3 .200 ha

7. P. N. da Serra da Bocaina (SP-RJ): 1971 100.000 há 
8. P. N. do Superagui (PR): 1989 21.000 ha

9. P. N. do Iguaçu (PR): 1939 185.000 há

10. P. N. de São Joaquim (SC): 1961 .49 .000 ha

11. P. N. dos Aparados da Serra (SC-RS): 1959 10.250 ha

12. P. N. da Serra Geral (SC-RS): 1992 17.300 ha

Desses doze parques nacionais, o P. N. da Serra dos Órgãos, o P. N. da Tijuca e o P. N. do Iguaçu abrangem exclusivamente a Mata Atlântica. Os demais cobrem formações vegetais diversas. Os parques nacionais da Região Sudeste preservam a Mata Atlântica e os campos de altitude; já os parques nacionais da Região Sul preservam a Mata Atlântica, a Mata de Araucárias e os campos limpos, ditos "Campos Gerais". Pelo fato de se estenderem até o litoral, ou pelo litoral, o P. N. do Monte Pascoal, o P. N. do Descobrimento e o P. N. do Superagüi preservam a Mata Atlântica, as matas de restinga, os manguezais e a vegetação de praia, ecossistemas diferenciados, que disputam espaços com substratos diferentes. A Região Nordeste conta apenas com o P. N. do Monte Pascoal e o P. N. do Descobrimento, que visam preservar sobretudo a Hiléia Baiana. Daí para o norte, os pequenos trechos florestais remanescentes, capoeiras e capoeirões, se não estiverem sob a proteção estadual, correm sério risco de desaparecimento, ou de empobrecimento de sua biota. Câmara (1997, p. 171) afirma que,

no restante da mata pluvial, ao norte do Monte Pascoal, a situação se torna agudamente crítica. Não existe qualquer unidade de conservação em área de floresta, com extensão significativa, e as matas residuais são todas pequenas, em acentuado processo de redução e deterioração devido ao avanço da agricultura canavieira e à prática da caça ilegal.

Com exceção os parques nacionais, existem vários parques estaduais, reservas biológicas e estações ecológicas, disseminados por vários estados e com a mesma finalidade conservacionista. Salvo raras exceções, na Região Nordeste não há nenhuma área destinada à preservação da quase extinta Mata Atlântica.

Paradoxalmente, é o Estado de São Paulo a unidade da federação que conta como o maior porcentual de Mata Atlântica preservada, com área total em torno de $60 \%$ da mesma. Visando proteger consideráveis parcelas dessa mata, o Governo Estadual promoveu a criação de várias áreas destinadas à proteção do meio ambiente, da floresta e da fauna nativas. Muitos acidentes geográficos, de grande apelo turístico, como cachoeiras e cavernas, foram valorizadas e passaram a fazer parte dessas áreas de preservação. 
No biênio 1984-1985 foi criada, pelo Governo Estdual, a APA Cananéia-IguapePeruíbe, com 202.832 hectares, abrangendo os municípios de Cananéia, Itariri, Ilha Comprida, Iguape, Pedro de Toledo, Miracatu e Peruíbe. “As APAs (Áreas de Preservação Ambiental) são partes do território nacional especialmente protegidas por lei, visando harmonizar a preservação dos recursos naturais com o desenvolvimento social e econômico, capaz de produzir e melhorar a qualidade de vida das comunidades envolvidas". No âmbito dessa APA encontram-se o Parque Nacional do Superagüi - e a Estação Ecológica Juréia-Itatins. Entre Peruíbe e Paranaguá situa-se o Complexo Estuarino e Lagunar Iguape-Paranaguá, área natural de preservação que procura proteger sobretudo os manguezais e as matas de restinga, considerado um importante santuário ecológico. Mais para o interior, no Vale do Ribeira, existe o Parque Estadual de Jacupiranga, com 150.000 hectares. É justamente nessa área que se encontra a maior parcela de Mata Atlântica contínua no país.

Nas altas encostas e nos topos da Serra de Paranapiacaba, que, pelo interior, circunda a Baixada do Ribeira, o Governo Estadual criou o Parque Estadual Turístico do Alto Ribeira (Petar), o Parque Estadual Intervales (ex-Fazenda Intervales), o Parque Estadual Carlos Botelho, o Parque Estadual do Jurupará e a Estação Ecológica do Xitué, todos interligados, totalizando 146.300 hectares. Nessas áreas estão contidos trechos consideráveis dos municípios de Apiaí, Iporanga, Barra do Turvo, Eldorado Paulista, Sete Barras, Ribeirão Grande, Ibiúna e Piedade. No Petar, entre Apiaí e Iporanga, encontra-se a maior concentração de cavernas do Brasil, devido a possantes afloramentos de calcários proterozóicos do Grupo São Roque, com baixo grau de metamorfismo. Em virtude disso, esse parque estadual passou a ser uma grande atração para os espeleólogos e para os praticantes de cavernismo ("caving"), que para lá anualmente afluem em grande número. O Rio Betari, pequeno afluente do Rio Ribeira de Iguape, pela margem esquerda, que cruza o parque em meio à mata, tem sido utilizado na prática do "boiacross". Também o Parque Estadual Intervales recebe, com freqüência, muitos ecoturistas e caravanas de estudantes, adeptos do cavernismo e do "hikking" (caminhadas curtas) pelas trilhas da mata. Entre Mogi das Cruzes e Bertioga (SP), nas encostas da Serra do Mar, foi criado o Parque Estadual das Neblinas.

A fim de incrementar o turismo ecológico na região de Iguape, Ilha Comprida, Cananéia e Pariquera-Açu, A fundação S.O.S. Mata Atlântica, com patrocínio da Embratur, criou o Pólo Ecoturístico do Lagamar, na utilização sustentável dos recursos naturais, incluindo entre suas práticas habituais, caminhadas pelas matas e 
pelas praias, banhos em cachoeiras, passeios de canoa, visita a sítios arqueológicos e a centros históricos (Iguape, Cananéia), etc.

Entre os estados de São Paulo e Rio de Janeiro, em território paulista, localiza-se o Parque Estadual da Serra do Mar, com 309.030 hectares, onde a mata densa reveste as altas encostas e os profundos vales e grotões dessa serra. No Estado de Santa Catarina foi criado o Parque Estadual da Serra do Tabuleiro, importante unidade de preservação da mata, não longe do litoral. Finalmente, resta-nos fazer breve referência ao minúsculo Parque Estadual da Serra da Cantareira, na periferia norte da cidade de São Paulo, e ao Parque Estadual de Ilhabela, situado na Ilha de São Sebastião (SP).

\section{CONCLUSÃO}

Pelo que temos lido e ouvido, persiste entre os especialistas uma certa dúvida sobre a verdadeira abrangência da Mata Atlântica, especialmente na sua parte meridional, onde ela se expande mais para o interior, até atingir a calha do Rio Paraná. Análises geográficas mais acuradas, feitas a seu respeito, considera a floresta higrófila perenifólia como sendo a verdadeira Mata Atlântica, situada, descontinuamente, mais próximo ao litoral; a outra parte dela, ocupando extensos trechos do interior (fase original), sobretudo na bacia do Paraná, teria, então, outra denominação: floresta tropical subcaducifólia, floresta tropical estacional ou floresta tropical semi-decídua. Todavia, estas são denominações de natureza biogeográfica geral, e não uma denominação geográfica brasileira ou sul-americana. Continua sendo um assunto polêmico.

Zonal ou meridiana? Considerada em escala global ou planetária, a Mata Atlântica é uma formação vegetal zonal, pois localiza-se na zona intertropical, e numa pequena extensão na zona subtropical, correspondendo, em latitude, a outras formações congêneres do mundo; já em escala continental, sul-americana, a Mata Atlântica é uma formação vegetal meridiana, pelo fato de estender-se no sentido norte-sul do continente, paralelamente ao litoral atlântico.

Os trechos florestais ainda restantes são objeto de admiração, mas também de preocupação permanente no que tange à sua preservação, pois a irresponsabilidade humana não tem escrúpulos e nem limites. Tomando consciência de sua exagerada diminuição territorial, e até da sua eventual extinção, um grupo de pessoas idealistas criou a Fundação S.O.S. Mata Atlântica, em 1986, uma ONG com sede em São Paulo, destinada a divulgar essa floresta e denunciar as agressões cometidas contra ela. 
$\mathrm{Na}$ esfera federal, o Ibama (Instituto Brasileiro do Meio Ambiente e dos Recursos Naturais Renováveis), criado em 22 de fevereiro de 1989, tem prestado relevantes serviços na proteção à flora, à fauna e a outros recursos naturais da Mata Atlântica. O Ibama é uma entidade subordinada ao Ministério do Meio Ambiente, responsável pela gestão dos parques nacionais e das reservas ecológicas federais. Realiza, também, um constante trabalho de vigilância e de fiscalização sobre o patrimônio florístico e faunístico da Mata Atlântica e dos demais biomas do país.

\section{REFERÊNCIAS}

AB'SABER, A. N. O domínio dos mares de morros no Brasil. São Paulo: Universidade de São Paulo, Instituto de Geografia, 1966. (Geomorfologia, 2).

. Um exemplo a não ser seguido. Ciência Hoje. Rio de Janeiro: SBPC, ano 1, n. 1, p. 20-21, jul-ago, 1982.

ANDRADE, M. C. A terra e o homem no Nordeste. São Paulo: Atlas, 1986. p. 22-48.

AZEVEDO, L. G. Tipos de vegetação. In: Atlas do Brasil. Rio de Janeiro: Conselho Nacional de Geografia, IBGE, 1960. p. 511-520.

BERNARDES, L. M. C. Clima. In: Atlas do Brasil. Rio de Janeiro: Conselho Nacional de Geografia, IBGE, 1960. p. 497-509.

BRANCO, S. M. O fenômeno Cubatão. São Paulo: CETESB/ASCETESB, 1984. p. $75-85$.

CÂMARA, I. G. Conservação da Mata Atlântica. In: Mata Atlântica/Atlantic rain Forest. São Paulo: Fundação S.O.S. Mata Atlântica/Index, 1991. p. 161-172.

CAVAlCANTE, A. Jardins suspensos no Sertão. Scientific American, Brasil. São Paulo, ano 3, n. 2, p. 66-73, jan. 2005.

CRUZ, O. A Serra do Mar e o litoral na área de Caraguatatuba-SP. São Paulo: Universidade de São Paulo, Instituto de Geografia, 1974. 181p.

DEAN, W. A ferro e fogo: a história e a devastação da mata atlântica brasileira. São Paulo: Companhia das Letras, 2004. 484p.

DENIS, P. Amérique Du Sud. Paris: Armand Colin, tome XV, 1927. 210p. (Géographie Universelle). 
DOMINGUES, A. J. P.; KELLER, E. C. S. Bahia. In: CONGRESSO INTERNACIONAL DE GEOGRAIA, 18, 1958, Guia de excursão, n. 6, Rio de Janeiro: CNG/IBGE, 1958. p. 102-109.

FREYRE, G. Nordeste: aspectos da influência da cana sobre a vida e a paisagem do Nordeste do Brasil. Rio de Janeiro: José Olympio, 1961. p. 43-61.

IBAMA - Instituto Brasileiro do Meio Ambiente e dos Recursos Naturais Renováveis. Parques nacionais: Brasil. Brasília/SãoPaulo: Empresa das Artes, 1987. 187p.

JOLY, C. A.; LEITÃO FILHO, H. F.; SILVA, S. M. O patrimônio florístico. In: Mata Atlântica/Atlantic rain forest. São Paulo: Fundação S.O.S. Mata Atlântica/Index, 1991. p. 97-107.

LIMA JR, A. A Capitania das Minas Gerais. Belo Horizonte/São Paulo: Itatiaia/Edusp, 1978. 140p.

MARCHIORI, J. N. C. Fitogeografia do Rio Grande do Sul: campos sulinos. Porto Alegre: EST, 2004. 110p.

OLIVEIRA FILHO, A. T.; RATTER, J. A. Padrões florísticos das matas ciliares da região do cerrado e a evolução das paisagens do Brasil Central durante o Quaternário tardio. In: Matas ciliares: conservação e recuperação. São Paulo: EDUSP, 2000. p. 73089.

PRADO JR, C. História econômica do Brasil. São Paulo: Brasiliense, 1959. 348p.

RIZZINI, C. T. Tratado de fitogeografia do Brasil. São Paulo: Hucitec/EDUSP, 1979. 374p. v. 2.

RIZZINI, C. T.; COIMBRA FILHO, A. F. Ecossistemas brasileiros/Brazilian ecosystems. Rio de Janeiro: Indez, 1988. p. 50-69.

ROMARIZ, D. A. A vegetação. In: Brasil, a terra e o homem. São Paulo: Companhia Editora Nacional, 1964. v. 1. p. 485-514.

VASCONCELOS SOBRINHO, J. As regiões naturais do Nordeste, o meio e a civilização. Recife: Conselho de Desenvolvimento de Pernambuco, 1970. p. 61-96.

WETTSTEIN, R. R. Plantas do Brasil: aspectos da vegetação do sul do Brasil. São Paulo: Edgard Blucher/Edusp, 1970. p. 22-94. 
